\title{
“Analyze \& Focus Your Intention" as the First Step for Applying the Digital Innovation and Transformation Process in Zoos
}

\author{
${\text { Matthias Wißotzki }{ }^{1 *} \text { and Johannes Wichmann }}^{1,2}$ \\ ${ }^{1}$ Wismar University of Applied Sciences, Philipp Müller Str. 14, 23966 Wismar, \\ Germany \\ ${ }^{2}$ Rostock University, Albert-Einstein-Straße 22, 18059 Rostock, Germany \\ \{matthias.wissotzki, johannes.wichmann\}@hs-wismar.de
}

\begin{abstract}
In many industrial domains and service sectors, digitalization efforts show first results. New kinds of products and services were introduced, which would not have been possible without end-to-end digitalization of operational processes, continuous collection and evaluation of data about product use and evaluation of customer data or activities. Facing the challenge of customer satisfaction in terms of leisure activities, zoos are in need to modernize their tours and attendances. Therefore, this article describes the application of the Digital Innovation and Transformation Process (DITP) in animal-gardening facilities, as it collects, analyzes and structures information of 19 facilities within the "Landeszooverband Mecklenburg-Vorpommern e.V." and combines them with qualitative studies. The research aims to analyze and focus the companies' intention for the digitization of zoos by using the first phase of the DITP. Possible business concepts, related works and best practices were gathered and are the basis for further research and applications.

Keywords. Digital Innovation, Digital Transformation, Business Modeling, Enterprise Modeling, Capability Management, Enterprise Architecture Management, EAM, Business-IT-Alignment, Digital Zoos, Virtual Zoos.
\end{abstract}

\section{Introduction}

For many companies, digital or semi-digital products are already an important part of their business model, with an increasing propensity. In order to take advantage of the opportunities offered by digitalization, companies will have to continuously develop new application areas or transform existing ones by using technologies. In this context, science and practice are increasingly concerned with the preparation and conceptualization of this topic in order to use the potential for new, in particular digitally supported, formats more quickly and to be able to better cope with the resulting challenges.

\footnotetext{
* Corresponding author

(C) 2019 Matthias Wißotzki et al. This is an open access article licensed under the Creative Commons Attribution License (http://creativecommons.org/licenses/by/4.0).

Reference: M. Wißotzki and J. Wichmann, ““'Analyze \& Focus Your Intention” as the First Step for Applying the Digital Innovation and Transformation Process in Zoos," Complex Systems Informatics and Modeling Quarterly, CSIMQ, no. 20, pp. 89-105, 2019. Available: https://doi.org/10.7250/csimq.2019-20.05

Additional information. PII S225599221900119X. Received: 15 October 2019. Accepted: 28 October 2019. Available online: 31 October 2019.
} 
The same is true for zookeepers' facilities, as these are also business organizations that want to and have to deal with the subjects of digitization, digitalization and digital transformation [1]. First, as part of the digitization, their analog services will be digitalized [2]. As the second step, the digitalization describes the outcomes concerning the respective business model [3] and, third ,the digital transformation represents the optimized transformation procedure from analogue to digital services [4]. To gain an advantage concerning the transformation from analogue to digital services, new innovative user experience formats have to be improved continuously with technological support [5]. Therefore, these institutions also have to progressively think about complementary and new digital business models due to the increasing digital networking, smarter automation possibilities, omnipresent access technologies as well as dynamic customer requirements.

Thus, new digital-based business models and their integration require methodical and technical approaches from different areas of information systems research facilitating the prerequisite digital transformation. The business model management (BMM), capability management (CM), enterprise modeling (EM) and enterprise architecture management (EAM) represent a spectrum of methodical and technical approaches, which have to be selected and applied according to specific use cases.

Our investigation addresses this methodical and technical integration by proposing the Digital Innovation and Transformation Process (DITP). The DITP has its focus on method support, and the Digital Business Architect (DBA) as a modern qualification profile for professionals in an enterprise working on innovation and transformation initiatives [6]. The DITP, in particular, enables the $D B A$ to moderate a modeling session as a part of the business executive team in an enterprise between business management and technology experts in order to support implementing their requirements under consideration of integrative Business-IT-Alignment concepts. DITP connects and integrates selected established techniques from BMM, CM, EM and $E A M$. This article introduces the first phase "Analyze \& Focus Your Intention" of the DITP by applying it to a specific use case in the zoo gardening facility sector. The research uses the phase as a structured approach to identify requirements for digital zoos through expert interviews and qualitative analyzes. Subsequently, the process is evaluated as it addresses, e.g. zoo administrations, enterprise architects and IT developers for zoos as the target group with the aim of obtaining impressions for the requirements of digital zoos. This research is an extension of a conference paper presented at the 11th Workshop on Information Logistics and Digital Transformation (ILOG) that was co-located with the 18th International Conference on Perspectives in Business Information Research (BIR) in Katowice, Poland, September 23-25, 2019 [1].

Concerning this investigation, Section 2 describes the DITP as the research background. Section 3 reflects related work within the area of digital zoos. Section 4 reflects the reference architecture and the introduction to the case study, whereas Section 5 analyzes digital zoos by combining the DITP with findings from related work and the reference architecture. For the Zoos of the "Landeszooverband Mecklenburg-Vorpommern e.V." different focuses and digital potentials have been derived from the experiences of the previous sections. Finally, the summary and outlook including further research approaches are presented in Section 7.

\section{Research Background}

As the definition of the term digitization differs from branch [7] to branch [8], various politically, scientifically and entrepreneurially motivated debates emerge that often lead to general results. Thus, we have to accept that digitization is sometimes multi or single technology based and can be simple or very complex, because the exact appearance depends on many variables (e.g. experience, degree of digitization, motivation, etc.) [6], [9]. Basically it became apparent, that within the environment of people and companies, a new level of interaction as a result of the digitalization emerged and some parts of the collaboration were even completely 
transferred into this [9], [10]. Moreover, as argued in the following, this process is more than just the transition from analog to digital, as whole business models as well as analytical descriptions concerning the digital components of a company originated from the development.

For this research we used the digital innovation and transformation process $(D I T P)$, which is supposed to support enterprises in technology-motivated or innovation-based motivated changes [6]. The DITP in its present version can be applied in the following scenarios: The Scenario 1 describes the situation of an existing enterprise which faces new product-related, customerrelated and / or competitive challenges due to digitalization and which needs to react on them promptly. In scenario 2, the procedure of implementing a business concept in a start-up is demonstrated. Scenario 3 represents a company situation without an urgent need of action regarding a digital transformation but where the company is interested in capitating its digital potentials and thus improving their business activities by complementing or expanding it.

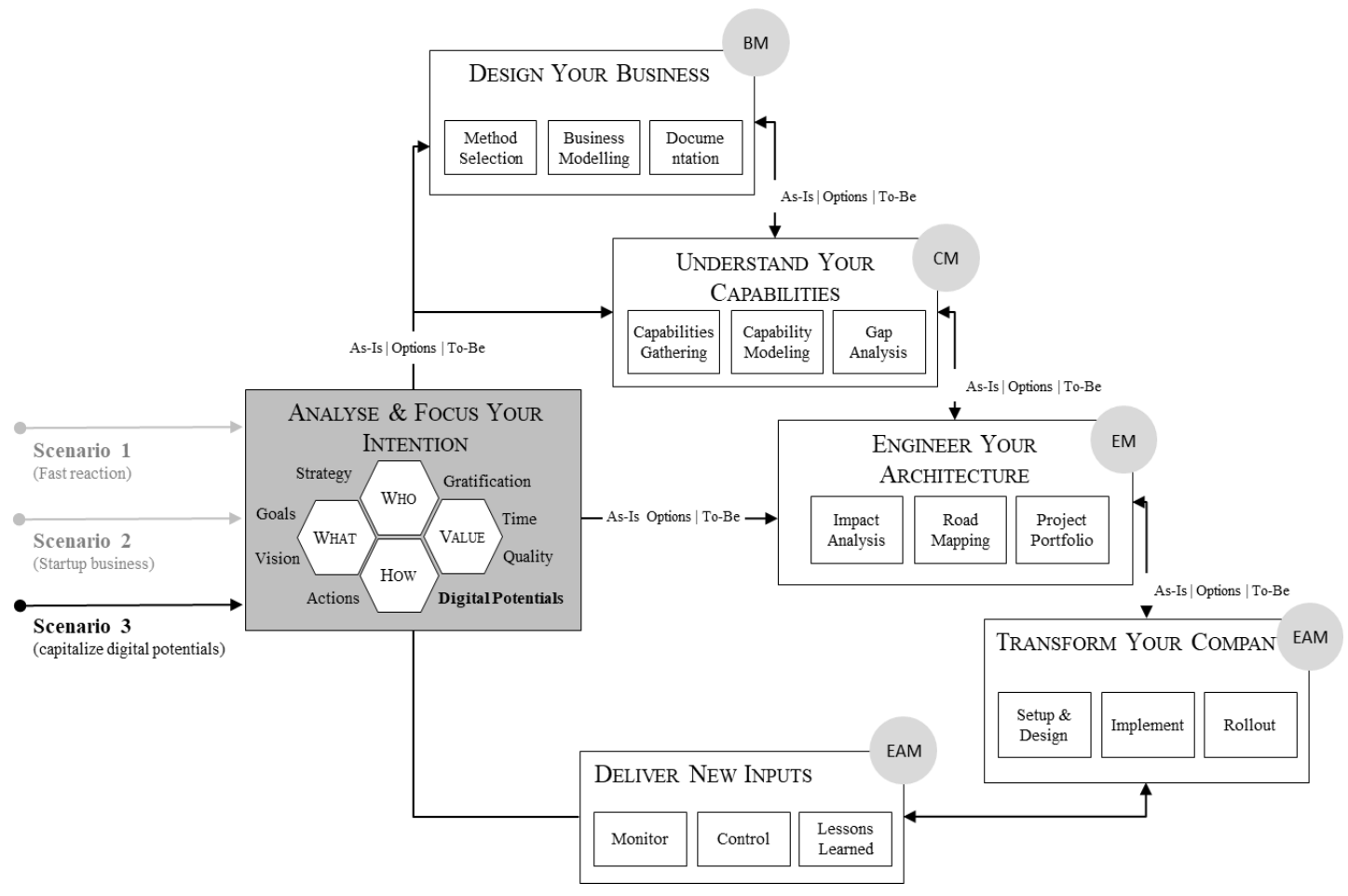

Figure 1. Digital Innovation and Transformation Process Approach, based on [6]

For this research, starting point for the investigation was the so-called „Analyze \& Focus Your Intention" phase in which existing ideas, goals, visions, strategies should be elaborated [6]. The output of this phase must have a clear business purpose. Therefore, the elaboration follows a participative goal trough process modeling, that helps to identify and formulate internal / external factors, requirements and implementation approaches, among others [11].

To provide a common methodological starting point, the activities for the elaboration of the basic intention are based on the conceptual development of a comprehensively documented business concept. Business concepts are the starting point for a business model, which is later operationalized by the enterprise architecture [12]. However, the components necessary to design a business model are not always obvious and manageable to a low-experienced company. Therefore, this process step uses an alternative version adapted in accordance with [6], [13]. The aim is to identify the basic intentions for digitalization projects of a company. Therefore, the process should consider four issues to focus the intention of an enterprise: DITP1.1 What, DITP1.2 Who, DITP1.3 How and DITP1.4 Value.

DITP1.1 What aims to develop the basic motivation for a digitization project. Vision, mission goals or strategy are considered important elements of corporate governance. Questions such as: What kind of intention is pursued? How does the wishfulness solution look like? Which goals should be reached to fulfill the intention? What is already existent or intended to be offered to 
the customer group or which promises of benefit should be communicated to the customer group? should help to describe the project more precisely [9], [14], [15]. DITP1.2 Who deals with the possible customer groups for the previously mentioned objectives. In this context, questions such as: What kind of stakeholders exist? Who is the recipient of the objective? What are the needs, the life situation, the willingness to pay and the value expectations of the customer group? Which added values and promises of benefit are generated? help [13], [16], [17]. How should the value proposition be operationalized within the framework of the value-adding activities? What kind of resources and partners are necessary for this? are sample questions, answered by DITP1.3 [13], [18]. In addition, DITP1.3 focuses on identifying digital trends, inspirations and best practices and helps to identify possible digital approaches that may be relevant for the development of the business concept [19]. Regardless of the project and motivation, each digitization project should be able to add value to the company. Thus, the DITP1.4 handles the question of the fulfillment that can arise for internal (e.g. employees) or external stakeholders (e.g. customers). For instance, the newly created digital capabilities, like networking or automation of work processes, the quality of products, and the improvement of working conditions or cost savings can be realized. This, in turn, could mean that the customer is able to buy products cheaper, faster and /or equipped with new features. Thus, the central question of the DITP1.4 arises with: Which value will be supplied to the company through the revenue model in conjunction with the cost and revenue structure? [13].

\section{Related Work}

In addition to the zoos' self-motivated digitization efforts, this topic is also subject of various researches. In addition to the tracking and identification of animals [2], there exist approaches: to gamification [5], [20], augmented reality [20], virtual guiding and navigation [21], [22], mobile learning applications [23], [24], [25] and digital content management systems [26]. The corresponding research approaches were evaluated and prepared accordingly for the case study and the application within the workshops. They serve, in addition to the expert meetings of the respective zoo administrations of the "Landeszooverband Mecklenburg-Vorpommern e.V.", as a basis and the characteristics for the qualitative analysis of Section 5 and the demands in Section 6.

\section{Digital Architectures in Zoos}

Starting point for the case study presented in this article is a cooperation with the "Landeszooverband Mecklenburg-Vorpommern e.V." aiming on the identification of digitization potentials, which was started in October 2018 [10], [27]. The association includes 19 companies, which organize themselves as a community of interest in the so-called "Landeszoo Akademie". The zoos, wildlife and nature discovery parks, tropical houses and aquariums within the federal state of Mecklenburg-Vorpommern work closely together in the academy. Their aim is to promote animal-breeding facilities in the state as sites of education, science, environmental protection, species and animal welfare. In total, the 19 companies annually attract more than three million visitors, including 60,000 pupils who experience active nature and species protection lessons directly on site. The zoo schools contain educational conditions that are not available in the most schools' classrooms [27].

In connection to the zoo's aims, digitalization offers many new opportunities for animal horticultural institutions, for instance, the enhancement of existing value creation and service provision with IT support and multimedia applications, or the development of entirely new or complementary business models [2], [11].

For combining digital advantages and the zoo experience, a descriptive model derived from the classical enterprise architecture (EA) will be used for our explanations. An EA denotes the fundamental conception or representation of an enterprise-as embodied in its main elements 
and relationships - in an appropriate model. EA models have evolved from mere IT architecture models into control instruments that can be used by the management as tools for their business decisions and allow an integrated view over a company. An $E A$ supports the understanding and documentation of an organizational structure with all dependencies on artifacts and information objects necessary for business performance [28]. Thus, the conceptualization of an enterprise architecture is about the exact construction of the value-adding processes, supporting technologies and the costs of the resources required for the construction.

To successfully develop an existing company concerning digital matters, appropriate planning activities must be carried out to assure that the effects of the targeted change and any resulting risks can be assessed. Therefore, the transferability of this context to the corporate environment of animal care facilities is obvious. To convey the activities known from the classic corporate architecture in a more standardized way for zoo garden facilities, a simple, animal-horticultural reference architecture was used as the starting point for the researches ongoing, based on the elements illustrated in Figure 2.

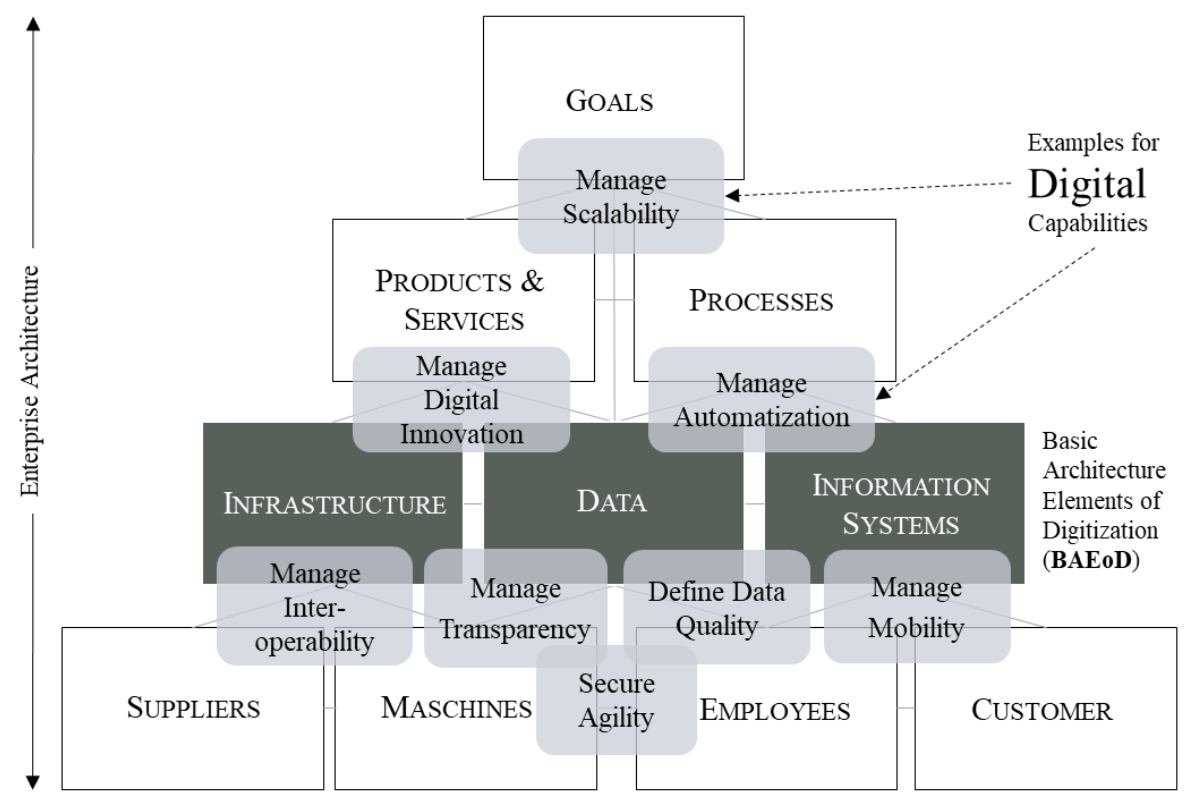

Figure 2. Reference Enterprise Architecture Approach for zoo gardening facilities, based on [10]

Each element represents a structural feature of the enterprise, which is characterized by different properties and relations. The elements infrastructure, information systems and data are present in every enterprise architecture and are characterized by their technology-based composition and their dependency on many other elements within the company. They are the basic architecture elements of digitization (BAEoD), which are visualized by Figure 2. Since the digital progress can take place in many areas of a company (multi-perspective approach), these $B A E O D$ inevitably have to be combined with other elements through horizontal and vertical integration [29]. With the resulting "digital capabilities", it is possible to work with zoo-gardening institutions to encounter the deliberation: "What digitization actually means for the respective institution" (Section 5). In conclusion, the development of $E A$, regardless of the kind of enterprise, requires the analysis and consideration of various stakeholders, which in turn is a fundamental part of the management of an enterprise architecture [29].

EA management (EAM) provides an approach for a systematic development of an enterprise's architecture in line with its goals by performing planning, transforming, and monitoring functions. The reasons for implementing an $E A$ via $E A M$ are manifold. On the one hand, it enables and supports the adaptation of IT to the business goals, the identification of problems or assistance coping challenges and, on the other hand, it allows a detailed description of the conjunction between business and IT [29]. 
The cooperation with the zoo gardening companies has shown that the spectrum of technological- or innovation-related changes is also very heterogeneous in this sector, which in turn affects the approaches and methods required for this. In addition to the aforementioned creation of enterprise architectures via enterprise modeling (EM) and management (EAM) methods, the community learned from other transformation projects [30], [31] that business modeling or capability modeling approaches can also be useful.

In order to assure that the approach for the "Landeszooakademie" can be realized for all zoos, regardless of the individual, digital maturity, the first phase of the DITP "Analysis \& Focus Your Intention" (Section 2) as a scenario 3 was triggered. To develop the content for this phase, various analysis activities were carried out (Section 5). Therefore, experts from three institutions of the "Landeszooakademie" (Zoo Schwerin, Zoo Rostock, Zoo Stralsund) were interviewed in the analysis phase about their goals, customers, processes, revenue models and possible digitization potentials and subsequently analyzed [32]. The results of the analysis were presented at the 4th Symposium of the "Landeszooakademie Mecklenburg-Vorpommern e.V." [10]. The results of the expert interviews were combined with a document-based study of the 16 remaining companies of the "Landeszooakademie Mecklenburg-Vorpommern e.V." and an internet-based qualitative analysis containing the analysis of 19 additional zoo gardening facilities. The collection of those additional zoos was based on two statistics concerning the number of visitors to the facilities [33], [34], whereby the nine largest zoo gardening facilities in Germany and the nine largest zoo gardening facilities in Europe were taken into account in our investigation. In this context, we are aware that this is not a repetitive quantitative data collection, but useful for a qualitative overview regarding its digital intention [35].

Both analyzes examined the questions: What are the current objectives of animal gardening facilities in the context of digitization (What)? How are the customers grouped together, nowadays and in the future (Who)? How is the subject of digitization currently handled in animal horticultural institutions (How)? Where have innovative digital approaches been implemented so far $($ How $)$ ? What does the average digital service portfolio of an animal gardening institution look like (Value)? The results will be summarized in the next section.

\section{Analyzing Zoo Visits in the Age of Digitization}

In the following, the analysis results of the 38 zoo gardening facilities are assigned to the focus areas of the "Analysis \& Focus Your Intention" phase (DITP1.1, DITP1.2, DITP1.3 and DITP1.4).

\subsection{DITP1.1: Vision, Goals and Strategies}

The facilities often aim to harmonize and digitize their cash register and access systems (BAEoD: Information System - see Section 4). The goal is to improve the customer journey substantially. The zoo guests basically pass through three stages, which can be divided in travel, stay and departure activities. At each stage, guests interact with different systems, which currently do not always have to be necessarily digital, e.g. upon arrival manual turnstiles or the visual access control. In the context of rising electronic and mobile ticket sales, the facilities are increasingly converting to integrated billing systems, which digitally link vending and parking lot machines, electronic turnstiles and thus access control across different channels, making them evaluable. Since the second stage follows seamlessly, the integrative use of a corresponding cash register system also affects guests' behavior on the property. In this context, approaches to cashless payment (e.g. restaurants, vending machines, various additional services) were frequently found during the analysis, but also modularized changes of areas within the facility made the management of guests more individualized (DITP1.4). Finally, the guests leave the facility and the last stage of the customer journey appears. Here, innovative access and point-of-service $(P O S)$ systems can be used to provide services, such as automated way out controls with time 
credits, additional payment machines in the parking lot or reverse vending machines for borrowed devices. The information collected through the different stages is merged into a corresponding POS system. The advantage for the respective facilities has arisen through the evaluation of this information, which is available to operators e.g. it helped to improve customeroriented payment methods, access points to the systems, movement patterns and purchasing behaviors on the system (DITP1.4).

\subsection{DITP1.2: Target Group}

In 2017, about 40 million people visited an animal gardening facility in the Association of Zoological Gardens e.V., generating a revenue of 300 million euro [36]. In Germany, 2.87 million people visit an animal-gardening facility at least three times a year [37]. The largest group of zoo visitors in 2013 were, with $61 \%$ families with children, followed by adolescents (14-17 years) with $34 \%$ and young adults (18-24 years) with 29\% [38].

In particular, the above-mentioned age groups could be analyzed as part of a customer group analysis, taking into account considerations of field research, e.g. spatial and social behavior, population density, food ecology and population structure. Obviously, large amounts of the customers are so-called "digital natives". Those participants belong to the generation that grew up in the digital age [39]. Both in the private and in the work environment, digital changes are one of their fundamentals in their daily businesses. Dealing with these changes is relatively easy for them and often perceived as an improvement of the status quo. In the field of social behavior, the handling of social media, such as Facebook, Twitter, Instagram, Pinterest and YouTube is an integral part of the daily interaction. In particular, the shift within the entire guests' population structure in the direction of digital natives points to the need of a digitized approach and adjusted management to improve the customer journey.

\subsection{DITP1.3: Digital Potentials and Actions}

This section involves activities like: Research of digital trends and Identification of digital potentials in terms of best practices. Based on the documented aspects of DITP 1.1 and DITP 1.2, the first activity (Research of digital trends) allows the research of different data sources in order to determine digital trends such as Gartner Hype Cycle [40], Technology Radar [41], TechTrends [42] or Producthunt [43]. According to those digital trends, an analysis of best practices took place involving 38 zoo gardening facilities. In cooperation with the "Landeszooverband Mecklenburg-Vorpommern e.V.", those best practices were transformed into digital potentials and actions that are of particular relevance for zoological gardens of the future [10].

The following tables of the examined zoos represent overviews of those digital potentials and actions. The characteristics were: the integrated sale of paperless online tickets, the possibility of mobile donation, the existence of an interactive zoo plan, the ability to create personal zoo routes, the presence of a virtual tour and augmented reality measures as well as the existence of social media marketing activities. Table 1 describes the situation of the zoos of the qualitative analysis and subsequently Table 2 the situation of the members of the "Landeszooverband Mecklenburg-Vorpommern e.V.”.

Concerning the paperless e-tickets, the qualitative analysis determined that online tickets for zoos are already widely used internationally and thus a variety of examples is available. Similar findings have been gained for online donations and sponsorships - many zoos provide an online script or plugin for donations, but after all, almost all zoos surveyed have the account information of their donor account online. Regarding the interactive zoo plan and the following digital potentials and actions, the number of examples decreases so that the table has been enriched with a specific category called "best practice". These best practices serve as models for possible implementations within the "Landeszooverband Mecklenburg-Vorpommern e.V.". Best 
practices in terms of the interactive zoo plan is the Leipzig Zoo [45], which provides a plan that enables the visitor to define its own route concerning special features, such as catering, playgrounds, sanitary facilities, service points or souvenir shops.

Table 1. Digital Potentials and Actions Zoos Worldwide

\begin{tabular}{|c|c|c|c|c|c|c|c|}
\hline Zoo & 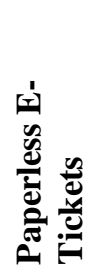 & 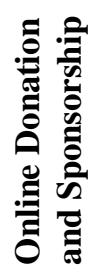 & 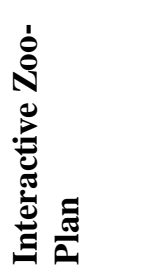 & 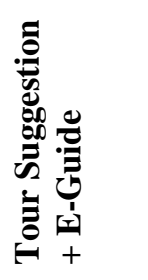 & 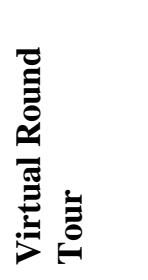 & 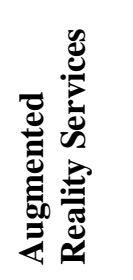 & 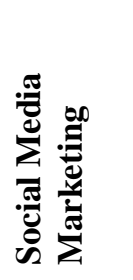 \\
\hline Osnabrück Zoo & $\mathbf{Y}$ & $\mathbf{Y}$ & $\mathbf{P 3}$ & $\mathbf{P 4}$ & $\mathbf{N}$ & P7 & $\mathbf{Y}$ \\
\hline Karlsruhe Zoo & $\mathbf{N}$ & $\mathbf{P 1}$ & $\mathbf{P 3}$ & $\mathbf{P 4}$ & $\mathbf{N}$ & P7 & P8 \\
\hline Zoo Vivarium Darmstadt & $\mathbf{N}$ & $\mathbf{P 2}$ & $\mathbf{P 3}$ & $\mathbf{N}$ & $\mathbf{N}$ & P7 & P8 \\
\hline Animal Park Gettorf & $\mathbf{N}$ & $\mathbf{N}$ & $\mathbf{P 3}$ & $\mathbf{P 4}$ & $\mathbf{N}$ & P7 & $\mathbf{Y}$ \\
\hline Wellington Zoo & $\mathbf{Y}$ & $\mathbf{Y}$ & $\mathbf{P 3}$ & $\mathbf{P 4}$ & $\mathbf{N}$ & P7 & BP [44] \\
\hline Bronx Zoo & $\mathbf{Y}$ & $\mathbf{Y}$ & $\mathbf{P 3}$ & $\mathbf{P 4}$ & $\mathbf{N}$ & P7 & $\mathbf{Y}$ \\
\hline Leipzig Zoo & $\mathbf{Y}$ & $\mathbf{P 1}$ & BP [45] & $\mathbf{P 4}$ & $\mathbf{Y}$ & $\mathbf{P 7}$ & $\mathbf{Y}$ \\
\hline Paignton Zoo & $\mathbf{Y}$ & $\mathbf{Y}$ & $\mathbf{P 3}$ & P5 & BP [46] & P7 & $\mathbf{Y}$ \\
\hline Dresden Zoo & $\mathbf{N}$ & $\mathbf{P 1}$ & $\mathbf{Y}$ & P5 & $\mathbf{N}$ & P7 & P8 \\
\hline $\begin{array}{c}\text { Wien Zoo (Animal Garden } \\
\text { Schönbrunn) }\end{array}$ & $\mathbf{Y}$ & $\mathbf{Y}$ & $\mathbf{P 3}$ & P5 & $\mathbf{N}$ & P7 & $\mathbf{Y}$ \\
\hline Wuppertal Zoo & $\mathbf{N}$ & P1 & $\mathbf{P 3}$ & $\mathbf{P 4}$ & $\mathbf{N}$ & P7 & $\mathbf{Y}$ \\
\hline Animal Park Olderdissen & $\mathbf{N N}$ & $\mathbf{P 1}$ & P3 & P5 & $\mathbf{N}$ & P7 & P8 \\
\hline Heidelberg Zoo & $\mathbf{N}$ & $\mathbf{P 1}$ & P3 & $\mathbf{P 4}$ & $\mathbf{N}$ & P7 & $\mathbf{Y}$ \\
\hline Berlin Zoo & $\mathbf{Y}$ & $\mathbf{Y}$ & $\mathbf{Y}$ & BP [47] & $\mathbf{N}$ & P7 & $\mathbf{Y}$ \\
\hline Houston Zoo & $\mathbf{Y}$ & $\mathbf{Y}$ & P3 & $\mathbf{P 4}$ & P6 & P7 & $\mathbf{Y}$ \\
\hline Barcelona Zoo & $\mathbf{Y}$ & $\mathbf{Y}$ & $\mathbf{P 3}$ & $\mathbf{P 4}$ & BP & P7 & $\mathbf{Y}$ \\
\hline Sydney Zoo (Taronga) & $\mathbf{Y}$ & $\mathbf{Y}$ & P3 & $\mathbf{P 4}$ & $\mathbf{N}$ & BP [48] & BP [48] \\
\hline $\begin{array}{l}\text { ZOOM World of Experience } \\
\text { Gelsenkirchen }\end{array}$ & $\mathbf{Y}$ & $\mathbf{N}$ & $\mathbf{P 3}$ & $\mathbf{P 4}$ & $\mathbf{N}$ & BP [49] & $\mathbf{Y}$ \\
\hline San Diego Zoo & $\mathbf{Y}$ & $\mathbf{Y}$ & $\mathbf{Y}$ & $\mathbf{Y}$ & P6 & P7 & $\mathbf{Y}$ \\
\hline $\begin{array}{l}\text { Table Description } \\
\begin{aligned} \text { Y } & =\text { yes } \\
\mathrm{N} & =\text { no } \\
\mathrm{P} & =\text { partly } \\
\mathrm{NN} & =\text { not necessary } \\
\mathrm{BP} & =\text { best practice (pattern } \\
\mathrm{P} 1 & =\text { only bank account inf } \\
\text { P2 } & =\text {.PDF form online } \\
\text { P3 } & =\text { online map available } \\
\text { P4 } & =\text { guided animal tours } \\
\text { P5 } & =\text { guided animal tours }( \\
\text { P6 } & =\text { animal webcams avail } \\
\text { P7 } & =\text { courses for educationa } \\
\text { P8 } & =\text { social media marketin }\end{aligned}\end{array}$ & $\begin{array}{l}\text { r gratifi } \\
\text { mation } \\
\text { th static } \\
\text { feedin } \\
\text { feedin } \\
\text { le } \\
\text { instituti } \\
\text { improva }\end{array}$ & $\begin{array}{l}\text { tion) } \\
\text { donatic } \\
\text { stead of } \\
\text { but no } \\
\text { but no }\end{array}$ & $\begin{array}{l}\text { online } \\
\text { teractive } \\
\text { ersonalizal } \\
\text { ersonaliza }\end{array}$ & + App & & & \\
\hline
\end{tabular}

Concerning the individualized tour suggestions as well as an e-guide, the Berlin Zoo [47] is exemplary. The facility uses an app and beacons to guide the visitors through the zoo by their own preferences and to live events, such as feedings or the optimized route to see all predators. 
Concerning the virtual round tour, the Paignton Zoo [46] offers the opportunity to stride through the whole facility online, via the zoo's website. The zoos in Sydney (Taronga) [48] and Gelsenkirchen [49] offer their visitors the opportunity to experience a more dedicated zoo attendance via augmented reality services. As an example, it is possible to change the point of view via virtual reality animations and glasses and to be among the animals, e.g. inside the meerkat tunnels. Furthermore, the zoos in Wellington [44] and Sydney [48] are considered best practices in terms of social media marketing as well, as they are represented on various platforms (e.g. Facebook, Twitter, YouTube, Instagram, Indeed) and very active on a regular basis to inform about the latest news and events. Then, in order to make an assessment of the state of digitalization of the respective zoological gardens of the "Landeszooverband MecklenburgVorpommern e.V.", an investigation was carried out simultaneously with the qualitative analysis for the facilities in the federal state. The results are presented in Table 2.

Overall, it can be recognized that the zoos in Mecklenburg-Vorpommern are, on average, less digitized than the companies of the qualitative analysis. The most advanced example in the federal state in terms of digitization is the Rostock Zoo. As a highlight, the facility provides an app including a virtual tour [50]. In addition, the zoo is very active on many social media platforms. It is conspicuous that some zoos, such as the Animal Garden Neustrelitz or the Wildlife in Usedom, provide a particularly low digitization level. During the symposium [10], the respective zoos mentioned that this fact is based on non-existent resources to digitize the own services. In addition, the Animal Park Grimmen does not have its own website and other zoos, such as the Nature Experience Park Mühlenhagen, do not have an HTTPS certificate, which makes access to the webpage extremely slow-velvet. All in all, it can be recognized that the degree of digitization varies greatly between the individual companies in the association. Due to the fact that it is declared goal of the "Landeszooverband Mecklenburg-Vorpommern e.V." to strengthen each other in terms of digitization projects [1], the following gratification as well as the focus and respectively the following research work are based on an integrated solution for the whole association. The aim is to ensure that small enterprises have access to digitization resources and that larger companies can increase the reach of their digital measures.

\subsection{DITP1.4: Gratification}

In order to structure and determine a focus regarding the selection of the determined digital potentials, it is important to clarify what kind of benefit the different possibilities can offer to the zoo gardening facilities. Therefore, the examined potentials were subjected to a future (To-Be) analysis [11]. The To-Be analysis aims to represent the issues improving the economic performance of a facility derived from digital potentials. The to-be analysis and the findings of the as-is study (Section 5.3) were inspired and enriched accordingly with the suggestions and wishes of the members of the "Landeszooakademie Mecklenburg-Vorpommern e.V." in the context of workshops and the symposium. For instance, the zoos in Mecklenburg-Vorpommern not only plan to have virtual round tours and augmented reality services in the future, but also plan to integrate them into an expanded concept of e-learning services. The results of those analyses as well as the assignment to $B A E O D$ (Section 4) for our study are summarized in Table 3. 
Table 2. Digital Potentials and Actions Zoos "Landeszooverband Mecklenburg-Vorpommern e.V."

\begin{tabular}{|c|c|c|c|c|c|c|c|}
\hline Zoo & 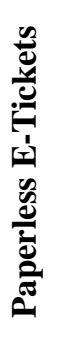 & 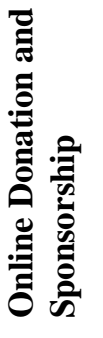 & 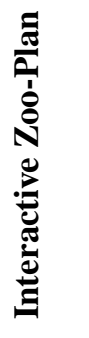 & 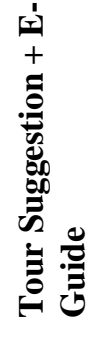 & 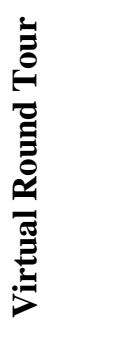 & 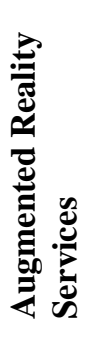 & 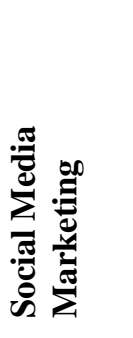 \\
\hline Schwerin Zoo & $\mathbf{N}$ & $\mathbf{Y}$ & P5 & P6 & $\mathbf{N}$ & P7 & $\mathbf{Y}$ \\
\hline Animal Park Wismar & $\mathbf{N}$ & $\mathbf{N}$ & P5 & $\mathbf{N}$ & $\mathbf{N}$ & $\mathbf{N}$ & P8 \\
\hline Rostock Zoo & $\mathbf{Y}$ & $\mathbf{P 3}$ & P5 & P6 & BP [50] & P7 & BP [50] \\
\hline Bird Park Marlow & $\mathbf{P 1}$ & $\mathbf{N}$ & P5 & P6 & $\mathbf{N}$ & $\mathbf{N}$ & P8 \\
\hline Wild Park MV & $\mathbf{N}$ & $\mathbf{P 3}$ & P5 & P6 & $\mathbf{N}$ & P7 & $\mathbf{Y}$ \\
\hline Müritzeum & $\mathbf{P 2}$ & $\mathbf{P 3}$ & P5 & P6 & BP [45] & P7 & P8 \\
\hline Pet Park Lelkendorf & $\mathbf{N}$ & $\mathbf{Y}$ & $\mathbf{N}$ & $\mathbf{N}$ & $\mathbf{N}$ & P7 & $\mathbf{Y}$ \\
\hline Animal Park Grimmen & $\mathbf{N}$ & $\mathbf{P 4}$ & P5 & $\mathbf{N}$ & $\mathbf{N}$ & $\mathbf{N}$ & P8 \\
\hline Animal Garden Neustrelitz & $\mathbf{N}$ & $\mathbf{N}$ & $\mathbf{N}$ & $\mathbf{N}$ & $\mathbf{N}$ & $\mathbf{N}$ & $\mathbf{N}$ \\
\hline $\begin{array}{l}\text { Nature Experience Park } \\
\text { Mühlenhagen }\end{array}$ & $\mathbf{N}$ & $\mathbf{P 3}$ & $\mathbf{N}$ & $\mathbf{N}$ & $\mathbf{N}$ & $\mathbf{N}$ & P8 \\
\hline Native Animal Park Greifswald & $\mathbf{N}$ & $\mathbf{P 3}$ & $\mathbf{N}$ & $\mathbf{N}$ & $\mathbf{N}$ & P7 & $\mathbf{N}$ \\
\hline Ozeaneum Stralsund & $\mathbf{Y}$ & $\mathbf{Y}$ & P5 & P6 & BP [51] & P7 & $\mathbf{B P}[51]$ \\
\hline Stralsund Zoo & $\mathbf{Y}$ & $\mathbf{P 3}$ & P5 & $\mathbf{N}$ & $\mathbf{N}$ & P7 & P8 \\
\hline Nature Experience Park Gristow & $\mathbf{N}$ & $\mathbf{P 3}$ & $\mathbf{N}$ & $\mathbf{N}$ & $\mathbf{N}$ & P7 & P8 \\
\hline Animal Park Ueckermünde & $\mathbf{P 2}$ & $\mathbf{P 3}$ & P5 & P6 & $\mathbf{B P}[1]$ & P7 & P8 \\
\hline Animal Park Wolgast & $\mathbf{N}$ & $\mathbf{P 3}$ & P5 & P6 & $\mathbf{N}$ & P7 & $\mathbf{P 8}$ \\
\hline Wildlife Usedom & $\mathbf{N}$ & $\mathbf{N}$ & $\mathbf{N}$ & $\mathbf{N}$ & $\mathbf{N}$ & $\mathbf{N}$ & P8 \\
\hline Tropical Zoo Bansin & $\mathbf{Y}$ & $\mathbf{N}$ & $\mathbf{N}$ & P6 & $\mathbf{N}$ & $\mathbf{N}$ & $\mathbf{N}$ \\
\hline Animal Park Sassnitz & $\mathbf{N}$ & $\mathbf{P 3}$ & $\mathbf{N}$ & $\mathbf{N}$ & $\mathbf{N}$ & $\mathbf{N}$ & $\mathbf{N}$ \\
\hline $\begin{array}{l}\text { Table Description } \\
\qquad \begin{array}{l}\text { Y }=\text { yes } \\
\mathrm{N}=\text { no } \\
\mathrm{P}=\text { partly } \\
\mathrm{BP}=\text { best practice (pattern for } \\
\mathrm{P} 1=\text { online tickets, but not par } \\
\mathrm{P} 2=\text { tickets orderable, receive } \\
\text { P3 }=\text { only bank account inform } \\
\text { P4 }=. \text { PDF form online } \\
\text { P5 }=\text { online map available, but } \\
\text { P6 }=\text { guided animal tours }(\mathrm{e} . \mathrm{g} . \\
\mathrm{P} 7=\text { courses for educational in } \\
\text { P8 }=\text { social media marketing ir }\end{array}\end{array}$ & $\begin{array}{l}\text { tificat } \\
\text { ess (p } \\
\text { ia pos } \\
\text { on for }\end{array}$ & $\begin{array}{l}\text { necessa } \\
\text { not pa } \\
\text { ation or } \\
\text { of inte } \\
\text { not per }\end{array}$ & $\begin{array}{l}\text { rless } \\
\text { ne } \\
\text { ctive } \\
\text { naliza }\end{array}$ & & & & \\
\hline
\end{tabular}


Table 3. Digital Potentials and Value for zoo gardening facilities

\begin{tabular}{|c|c|c|c|}
\hline Categories & $\begin{array}{l}\text { Digital Potentials } \\
\text { Identified Best } \\
\text { Practice }\end{array}$ & $\begin{array}{l}\text { Value } \\
\text { generated by: }\end{array}$ & $\begin{array}{l}\text { BAEoD } \\
\text { (Section 4) }\end{array}$ \\
\hline \multirow{3}{*}{ Sales } & Paperless E-Tickets & $\begin{array}{l}\text { Digital Parking Cards, Tickets, } \\
\text { Wallet, E-Tickets }\end{array}$ & IS \\
\hline & $\begin{array}{l}\text { Online Donation and } \\
\text { Sponsorship }\end{array}$ & $\begin{array}{l}\text { Mobile Donations, Sponsorships, } \\
\text { Mobile Payment Integration }\end{array}$ & Infrastructure, IS \\
\hline & Access and POS System & $\begin{array}{l}\text { Cohort-Analysis, Spatial Behavior, } \\
\text { Social Behavior, Population } \\
\text { Density, Food Ecology, Population } \\
\text { Structure }\end{array}$ & Infrastructure, IS, Data \\
\hline \multirow[b]{2}{*}{ Navigation } & Interactive Zoo Plan & $\begin{array}{l}\text { Information regarding POI as a } \\
\text { Service }\end{array}$ & IS \\
\hline & $\begin{array}{l}\text { Tour Suggestion + E- } \\
\text { Guide }\end{array}$ & $\begin{array}{l}\text { Customizable Routes, GPS- } \\
\text { Navigation, Live-Location Guide, } \\
\text { Location based Services (Indoor / } \\
\text { Outdoor) }\end{array}$ & IS, Data \\
\hline \multirow{2}{*}{ Edutainment } & Virtual Round Tour & $\begin{array}{l}360^{\circ} \text { Services, E-Learning- } \\
\text { Services }\end{array}$ & IS \\
\hline & $\begin{array}{l}\text { Augmented Reality } \\
\text { Services }\end{array}$ & E-Learning Services & IS \\
\hline Marketing & Social Media Marketing & $\begin{array}{l}\text { Identify / Activate / Sensitize } \\
\text { Digital Natives on Social Networks }\end{array}$ & Data \\
\hline \multicolumn{4}{|c|}{$\begin{array}{l}\text { Osnabrück Zoo, Karlsruhe Zoo, Darmstadt Vivarium, Gettorf Animal Park, Wellington Zoo, Bronx Zoo, Leipzig } \\
\text { Zoo, Paignton Zoo, Dresden Zoo, Wien Zoo, Wuppertal Zoo, Olderdissen Animal Park, Heidelberg Zoo, Berlin } \\
\text { Zoo, Houston Zoo, Barcelona Zoo, Sydney Zoo, Gelsenkirchen ZOOM World of Experience, San Diego Zoo, } 19 \\
\text { Members of the Zoo Academy Mecklenburg-Vorpommern }\end{array}$} \\
\hline
\end{tabular}

\section{Focus and Potentials for Digital Zoos}

Derived from the results of the analysis, a participatory workshop [11] with several prioritization stages was realized. The aim was to evaluate the digital potentials (Table 4) with the project partners in order to develop possibilities for the next level of DITP ("Design Your Business"). The evaluation of the determined potentials was also presented at the 4th Symposium of the "Landeszooakademie Mecklenburg-Vorpommern e.V." 2018 with representatives of the participants (basic population: $\mathrm{n}=19$ ) and sorted by priority [10]. Table 4 shows the result of the prioritized digitization topics. They were specified more appropriately by consulting the members on issues in Mecklenburg-Vorpommern.

Table 4. Evaluation result of Digital Potential for zoo gardening facilities in Mecklenburg-Vorpommern, based on [10]

\begin{tabular}{|l|c|}
\hline \multicolumn{1}{|c|}{ Digital Potentials } & Priority \\
\hline Online Forms and Mobile Donations & 5 \\
\hline Uniform Cash-Register and Access-System & 4 \\
\hline Mobile Zoo App & 3 \\
\hline Cloud-based Booking System & 2 \\
\hline
\end{tabular}




\subsection{Online Forms and Mobile Donations}

Nowadays, many things have to be quick to implement - thus, the topic of "impulse buying" also becomes important in the context of animal-gardening facilities. With the focus on "mobile payment per smartphone", the topic of sponsorships and (mobile) donations is of particular relevance, especially by considering that the guests mainly come in contact with the animals at the enclosures, aquariums and showcases. The customers are emotionally attached and aware of protecting these animals strongest while being at these places. However, there is currently no way to satisfy this need for protection locally via a digital service. Therefore, a possible solution could be a QR sticker leading to the mobile "on-site-donations" so that the guests are able to scan the code and pay immediately via mobile payment systems. The donation amount can be freely selected and paid by services as credit card, Apple Pay, Google Pay, PayPal, direct debit etc. The zoo receives the amount of donations through the specific payment provider to a predefined account. Furthermore, so-called location-based services could be used to determine the location of a person to a specific enclosure or to generate an optimized route of interest, e.g. a tour including all marine animals. After creating the donation app, the connection to a corresponding cash register or accounting system (see priority 4) would be a further expansion step, since the interaction of different systems via interfaces for customer relationship management (CRM) plays a very important role for improving business' performances. Considering this, all "donation transactions" can be automatically forwarded to the relevant systems and assigned to customers, which considerably simplifies the organizational effort for the operator system (e.g. automatic generation of donation receipts according to German tax law). In addition to the possibility of mobile donations, the same technology can also be used for the mobile acquisition of sponsorships, which should be billed and managed by the CRM. For instance, animal sponsors can be informed automatically about the expiration of their sponsorship and simply extend it online. An assisting CRM system plays an important role in the aforementioned possibilities. Regardless of whether the client is a simple app or site user, donor, animal sponsor, season ticket holder etc., user activity, active communication and contract management can all be analyzed and managed in these CRM systems. Of course, parallel to the mobile version of the donation via app, there should be the possibility to donate or apply sponsorships via the website of the institution, which also provides an integrative linking to the cash register or accounting system.

\subsection{Uniform Cash-Register and Access-System}

The cash register and access system is a key component of each individual zoo, but has become increasingly complex over time. In addition, online booking systems (priority 2) are considered important. In this context, it is relevant that the cash register system is able to communicate with other components (e.g. accounting system, app, CRM system) via interfaces or even include these systems themselves. A coherent cash register system within the "Landeszooverband Mecklenburg-Vorpommern e.V." would even comprise the advantage that the various installations in the individual zoos could automatically communicate with each other if required or could be jointly operated in a cloud, which could lead to a usage-dependent cost distribution of the operation. This would also simplify different campaigns, e.g. discounts for Zoo X with the season ticket from Zoo Y. However, this scenario can also be implemented via a nationwide coordinated interface architecture, which would be much more expensive in operational maintenance, because it is likely that maintenance processes have to be realized for each member separately. In connection with current POS systems and the target group, the possibility of cashless payment is becoming increasingly important [52]. This not only applies to tickets at the cash desk, but also for small amounts during the visit (e.g. snacks, drinks). The expectations of future visitors (Digital Natives) regarding the "everywhere cashless payment" - whether with electronic cash (EC) or credit card or smartphone - is present and zoos aim to encounter it. 
Technologically it is solvable by today, but has to be meaningfully integrated into the overall system, according to the workshop's result. In addition to the "standard" functions, current POS systems often offer compatible access systems, which may be particularly relevant for visitor analyzes. As an example: The ticket (whether analogue or digital) was scanned at the entrance and the exit turnstile. Thus, e.g. the duration of visits and movement patterns are recorded and based on this, valuable knowledge is derived for the operator. Other questions such as "What paths do my visitors use the most?", "Which are the most frequented playgrounds?", "Which enclosures are visited at what time?" can be answered with other technologies by analyzing customer behavior. Considering this, internal work processes (e.g. "How many employees do I need where and when?") can be optimized.

\subsection{Mobile Zoo App}

The existing possibilities of apps in relation to zoo gardening facilities have already been presented in analysis results (DITP 1.3) such as information on feeding, knowledge transfer, interactive zoo plan, personalized guided tour offers and point-of-interest navigation. However, there is also the challenge that it is nearly impossible, especially for smaller members of the Zoo Association, to operate their own app (due to development and maintenance costs). Thus, it would be advantageous to develop a central app. This application is intended to provide all the relevant information and services offered by the members of the "Landeszooverband". With the help of location-based services, where the user either selects or automatically locates his current position, the offer can be customized to suit the zoo's and the user's exact environment. An important factor is the view that an app is only one accessibility to a cloud platform (BAEoD: information system, data). The same data and services can also be retrieved by other means, such as websites or language assistants. A central cloud platform can therefore offer considerable benefit for all members of the association. Since the overall development effort for individual zoo-specific solutions will be significantly higher than a central solution, this approach could be an interesting alternative for members of the association. Further, other services could be covered by the app as well. In addition to the booking system, a mobile app can also include the digital annual pass or individual tickets (which is also relevant for the members of the association).

By integrating additional interfaces, new experience formats can be created, such as the Digital Assistant / Guide. By intelligently and controllably combining data and services, the user could execute e.g. digital-accompanied-themed or situational tours ("I would like to experience all feedings") through the facilities or could inform himself about the parking lot occupancy. Further possible uses for generating benefit are e.g. the active customer contact. By applying push messages, the user can be informed (on request) about current actions and events.

In this context, the topic of social media marketing or dealing with user activities reviews and criticism concerning the app is relevant. On the one hand, by applying this solution, thousands of users can be reached simultaneously, on the other hand, the internet users trust the online ratings of their network enormously. Trust is the foundation for building relationships of all kinds and for business commitments, especially branding and reputation in the Digital Age. Once this is achieved, the users take recommendations from their (social media) friends as an opportunity for their own shopping or a visit to the zoo. Ratings and online referrals are not only increasingly important to suppliers; they also provide a valuable and easy way to differentiate the marketplace. Thus, the social media use of an app, on the one hand, allows continuous contact with the growing target group of digital natives and faster responses to problems, request and queries. On the other hand, this in turn results in strategically meaningful knowledge about the target group, which leads to a constant improvement in product quality. 


\subsection{Cloud-based Booking System}

The most common digital solution is the online booking system, which is responsible for initiating and processing ticket purchases. In addition to selling tickets, horticultural institutions also offer other services that could be booked online. Examples are children's birthday parties, individual zoo tours or event tickets (e.g. night tour). The management of these bookings manually is only possible with great effort: as, on the one hand, regarding communication expenditures (receiving telephone calls, E-Mail conversations) and, on the other hand, the administrative activities (manual entry of bookings and various systems, calendars) are extremely time-consuming. The payment must also be processed and entered manually. In this context, a corresponding connection to the CRM system (priority 5) and POS system (priority 4) would be perfectly appropriate and therefore necessary. These systems can be embedded as a cloud solution both on the websites of the individual members as well as on the central website of the "Landeszooverband". In addition to the web pages, the same booking platform may, e.g. be also integrated into apps. Another step would be an access via voice subscribers (e.g. Amazon Alexa, Google Home, Apple Siri). The foundation for the established focus remains a suitable infrastructure (see $B A E O D$ infrastructure), as this is the starting point for the interplay of the individual systems and their components. In addition to the usual broadband issue, local networks (wired networks, WLAN) are also important.

The outcome of this phase was an overview with digital potentials that should be considered in the context of the "Design Your Business" step (Figure 1), which is currently in execution by the "Landeszooakademie".

\section{Summary \& Outlook}

In regard to the described process, it could be noticed that the first phase of the DITP called "Analyze \& Focus Your Intention" is applicable in zoological contexts. Concerning the target group (e.g. zoo administration, enterprise architects and IT developers for zoos), this research provides an indication of the potential digital development of zoos by best practices that show which digital topics are current in zoos. In relation to the region, the investigations during the analysis phase determined that good solutions and best practices for animal gardening facilities concerning the range of digitization potentials in the zoo facilities in Mecklenburg-Vorpommern already exist. Here, it should be emphasized that the zoos have additionally profited in gaining new impluses for further development by surpassing the "Analyze \& Focus Your Intention" phase - due to workshops as well as the qualitative analysis and the processing of the related work. A prerequisite for successful digitization projects is the focus on innovative ideas, the knowledge of their design, the activities required for the adaption or redesign, as well as the architectures involved within and outside the company. Regardless of the individual case, in order to realize these potentials successfully, a high degree of agility may be required, which is only then economically possible if the effects of changes in the company can be estimated accurately. To create these conditions and to establish them in the long term, it is also necessary to continue the projects within or outside the company, because digitization is not a static state but constantly in motion and this should be kept under observation. Thus, the development of new or the expansion of existing business models, with the help of the named BAEoD, will be further works' focus and professionally accompanied by the "Design Your Business" phase of DITP. Concerning the latter, the Digital Innovation and Transformation Process will be further developed, as it is currently implemented in a Smart City project to build an Enterprise Architecture within a region in Mecklenburg-Vorpommern. The first phase "Analyze \& Focus Your Intention" could be further developed by using the proposed procedure in further investigations in zoological contexts outside Mecklenburg-Vorpommern, in order to validate the results, as it is the limitation of the research that the investigation took place in a specific region. 


\section{References}

[1] M. Wißotzki and J. Wichmann, "Application of the Digital Innovation and Transformation Process in Zoo Gardening Facilities," Joint Proceedings of the BIR 2019 Workshops and Doctoral Consortium co-located with the 18th International Conference on Perspectives in Business Informatics Research (BIR 2019). CEUR Workshop Proceedings, vol. 2443, pp. 83-97, 2019.

[2] J. Karlsson, K. Ren, and H. Li, "Tracking and Identification of Animals for a Digital Zoo," IEEE/ACM Int'l Conference on Green Computing and Communications (GreenCom), 2010 \& Int'l Conference on Cyber, Physical and Social Computing (CPSCom), pp. 510-515. IEEE, 2010. Available: https://doi.org/10.1109/greencom-cpscom.2010.69

[3] Gartner, Digitalization, [Online]. Available: https://www.gartner.com/it-glossary/digitalization/. Accessed 2019/08/31.

[4] Gartner, Digital Transformation, [Online]. Available: https://www.gartner.com/it-glossary/digitaltransformation/. Accessed 2019/08/31.

[5] K. Fahlquist, T. Mejtoft, and J. Karlsson, "Social Media Game Concept within the Digital Zoo: New Ways of Connecting a Tourist Attraction with Its Visitors," International Conference on Internet of Things and 4th International Conference on Cyber, Physical and Social Computing (iThings/CPSCom), IEEE, pp. 170-177, 2011. Available: https://doi.org/10.1109/ithings/cpscom.2011.100

[6] M. Wißotzki and K. Sandkuhl, "The Digital Business Architect - Towards Method Support for Digital Innovation and Transformation," The Practice of Enterprise Modeling: 10th IFIP WG 8.1. Working Conference, PoEM 2017, Springer, LNBIP, vol. 305, pp. 352-362, 2017. Available: https://doi.org/10.1007/978-3-319-70241-4_24

[7] L. Otto, L. Harst, H. Schlieter, B. Wollschlaeger, P. Richter, and P. Timpel, "Towards a Unified Understanding of eHealth and Related Terms - Proposal of a Consolidated Terminological Basis," Proceedings of the 11th International Joint Conference on Biomedical Engineering Systems and Technologies, vol. 5, pp. 533-539, 2018. Available: https://doi.org/10.5220/0006651005330539

[8] C. M. Wells, "Total Digital Access to the League of Nations Archive: Digitization, Digitalization, and Analog Concerns," ARCHIVING 2019: Digitization, Preservation and Access - Final Program and Proceedings, pp. 12-16, 2019. Available: https://doi.org/10.2352/issn.2168-3204.2019.1.0.4

[9] W. Appelfeller and C. Feldmann (Eds.), Die digitale Transformation des Unternehmens: Systematischer Leiffaden mit zehn Elementen zur Strukturierung und Reifegradmessung, Springer, 2018. Available: https://doi.org/10.1007/978-3-662-54061-9

[10] M. Wißotzki and H. Schleifer, "Zoo digital - Eine bedarfsgerechte Kombination von Natur \& Technologie: Potenzialanalyse neuer Erlebnisformate durch Digitalisierung," Viertes Symposium der Landes Zoo Akademie, pp. 10-19, 2018.

[11] K. Sandkuhl, J. Stirna, A. Persson, and M. Wißotzki (Eds.), Enterprise modeling: Tackling business challenges with the 4EM method, Springer, 2014. Available: https://doi.org/10.1007/978-3-662-43725-4

[12] V. V. Martynov, D. N. Shavaleeva, and A. I. Salimova, "Designing Optimal Enterprise Architecture for Digital Industry: State and Prospects," 2018 Global Smart Industry Conference, IEEE, pp. 1-7, 2018. Available: https://doi.org/10.1109/glosic.2018.8570159

[13] O. Gassmann, K. Frankenberger, and M. Csik, “The St. Gallen business model navigator," Working Paper, pp. $1-15,2013$.

[14] A. Rusnjak, "Entrepreneurial Business Modeling," Entrepreneurial Business Modeling, Springer, pp. 81-108, 2014. Available: https://doi.org/10.1007/978-3-658-03767-3_3

[15] B. W. Wirtz, A. Pistoia, S. Ullrich, and V. Göttel, "Business Models: Origin, Development and Future Research Perspectives," Long Range Planning, Elsevier, vol. 49, no. 1, pp. 36-54, 2016. Available: https://doi.org/10.1016/j.lrp.2015.04.001

[16] T. Kofler (Eds.), Das digitale Unternehmen, Springer, 2018. Available; https://doi.org/10.1007/978-3-662$57617-5$

[17] Y. L. Doz and M. Kosonen, "Embedding Strategic Agility," Long Range Planning, Elsevier, vol. 43, no. 2-3, pp. 370-382, 2010. Available: https://doi.org/10.1016/j.lrp.2009.07.006

[18] A. Osterwalder and Y. Pigneur (Eds.), Business model generation: A handbook for visionaries, game changers, and challengers. Wiley, Hoboken, N.J., USA, 2013. 
[19] K. I. Voigt, O. Buliga, and K. Michl (Eds.), Business Model Pioneers. How Innovators Successfully Implement New Business Models, Springer, 2017. Available: https://doi.org/10.1007/978-3-319-38845-8

[20] J. Perry, E. Klopfer, and M. Norton, “AR gone wild: Two approaches to using augmented reality learning games in zoos," Computer-Supported Collaborative Learning Conference (CSCL) Proceedings, no. 3, pp. 322-239, 2008.

[21] D. Saranyaraj, "The virtual guide for assisted tours using context aware system," International Conference on Signal Processing, Image Processing and Pattern Recognition (ICSIPR), vol. 1, art. No. 6497973, 2013. Available: https://doi.org/10.1109/ICSIPR.2013.6497973

[22] P. Kapoun, J. Kapounová, "Instruction outside the classroom: Mobile, or ubiquitous learning?" Proceedings of the European Conference on e-Learning (ECEL), pp. 340-349, 2016.

[23] I. Boticki, J. Baksa, P. Seow, and C. K. Looi, "We are going to the ZOO! Virtual Badges in formal out-ofschool 1:1 learning Journey with Smartphones," Workshop Proceedings of the 22nd International Conference on Computers in Education (ICCE), pp. 710-715, 2014.

[24] P. A. Garcia Gaona, D. Martin Moncunill, K. Gordillo et al. "Navigation and Visualization of Knowledge Organization Systems using Virtual Reality Glasses," IEEE Latin America Transactions, vol. 14, no. 6, pp. 2915-2920, 2016. Available: https://doi.org/10.1109/TLA.2016.7555275

[25] A. B. Craig, E. R. Brown, J. Upright, and M. E. DeRosier, "Enhancing Children's Social Emotional Functioning Through Virtual Game-Based Delivery of Social Skills Training," Journal of Child and Family Studies, vol. 25, no. 3, pp. 959-968, 2016. Available: https://doi.org/10.1007/s10826-015-0274-8

[26] T. Ando, T. I shida, N. Uchida, and Y. Shibata, "Proposal of the Digital Contents Management System Utilizing the AR Technology," Proceedings of the 9th International Conference on Innovative Mobile and Internet Services in Ubiquitous Computing (IMIS), pp. 141-146, 2015. Available: https://doi.org/10.1109/IMIS.2015.23

[27] Landeszooverband Mecklenburg-Vorpommern e.V., Verband in Zahlen - Statistik, http://www.landeszooverband-mv.de/verband_in_zahlen.php

[28] G. Bondel, A. Faber, and F. Matthes, "Reporting from the Implementation of a Business Capability Map as Business-IT Alignment Tool," 2018 IEEE 22nd International Enterprise Distributed Object Computing Workshop (EDOCW) Proceedings, pp. 125-134. IEEE, 2018. Available: https://doi.org/10.1109/EDOCW.2018.00027

[29] I. Puspitasari, "Stakeholder's expected value of Enterprise Architecture: An Enterprise Architecture solution based on stakeholder perspective," 2016 IEEE/ACIS 14th International Conference on Software Engineering Research, Management and Applications (SERA): Proceedings, IEEE, pp. 243-248, 2016. Available: https://doi.org/10.1109/SERA.2016.7516152

[30] K. Sandkuhl, M. Wißotzki, A. Smirnov, and N. Shilov, "Digital Innovation Based on Digital Signage: Method, Categories and Examples," Perspectives in business informatics research: 17th international conference: BIR 2018, Springer, LNBIP, vol. 330, pp. 126-139, 2018. Available: https://doi.org/10.1007/978-3-319-99951-7_9

[31] K. Sandkuhl, A. Smirnov, N. Shilov, and M. Wißotzki, “Targeted Digital Signage: Technolo-gies, Approaches and Experiences," Internet of Things, Smart Spaces, and Next Generation Networks and Systems, Bd. 11118. [S.I.], Lecture Notes in Computer Science, Springer, Heidelberg, pp. 77-88, 2018. Available: https://doi.org/10.1007/978-3-030-01168-0_8

[32] P. Mayring, "Qualitative Inhaltsanalyse," Handbuch Qualitative Forschung in der Psychologie, 1st ed., VS Verlag für Sozialwissenschaften (GWV), Wiesbaden, no. 1., pp. 601-613, 2010. Available: https://doi.org/10.1007/978-3-531-92052-8_42

[33] Statista.de, Ranking der größten Zoos in Deutschland nach Zahl der Tiere im Jahr 2018. [Online]. Available: https://de.statista.com/statistik/daten/studie/314716/umfrage/groesste-zoos-in-deutschalnd-nach-anzahl-dertiere/. Accessed 2019/05/24.

[34] Statista.de, Ranking der größten europäischen Zoos nach der genutzten Fläche im Jahr 2015. [Online]. Available: https://de.statista.com/statistik/daten/studie/762998/umfrage/groesste-europaeische-zoos-nachflaeche/. Accessed 2019/05/24.

[35] H. Österle, et al., "Memorandum on design-oriented information systems research," European Journal of Information Systems, Palgrave Macmillan, London, vol. 20, no. 1, pp. 7-10, 2011. Available: https://doi.org/10.1057/ejis.2010.55 
[36] Verband der Zoologischen Gärten e.V., Zoos erwirtschaften 300 Millionen Euro Umsatz. [Online]. Available: https://verbaende.com/news.php/Zoos-erwirtschaften-300-Millionen-Euro-Umsatz-VdZ-fordert-Signal-vonParteien-in-Sondierungsgespraechen?m=118546. Accessed 2019/05/24.

[37] Statista.de, Bevölkerung in Deutschland nach Häufigkeit des Besuchs von Zoos und Tierparks in den Jahren 2015 bis 2018. [Online]. Available: https://de.statista.com/statistik/daten/studie/290972/umfrage/umfrage-indeutschland-zur-haeufigkeit-des-besuchs-von-zoos-und-tierparks/. Accessed 2019/05/13.

[38] Statista.de, Besucherstruktur von Zoos und Tierparks in Deutschland in 2013. [Online]. Available: https://de.statista.com/statistik/daten/studie/261497/umfrage/umfrage-zur-besucherstruktur-von-zoos-undtierparks-in-deutschland/. Accessed 2019/05/17.

[39] A. Dingli, and D. Seychell, The new digital natives: Cutting the chord. Springer, Berlin, 2015.

[40] Gartner, “Gartner Hype Cycle,” [Online]. Available: http://www.gartner.com. Accessed 2019/05/13.

[41] ThoughtWorks, “Technology Radar," vol. 20. [Online]. Available: https://www.thoughtworks.com/de/radar, Accessed 2019/05/13.

[42] Deloitte, "Deloitte Tech [Online]. Trends," Available: https://www2.deloitte.com/global/en/pages/technology/articles/tech-trends.html. Accessed 2019/05/13.

[43] Producthunt, Producthunt Portfolio, [Online]. Available: https://www.producthunt.com/. Accessed 2019/05/13.

[44] Wellington Zoo, [Online]. Available: https://wellingtonzoo.com/. Accessed 2019/10/10.

[45] Leipzig Zoo, “Interactive Zoo Plan," [Online]. Available: https://www.zoo-leipzig.de/interaktiverzooplan/\#begin-content. Accessed 2019/10/11.

[46] $360^{\circ} \quad$ Imagery, Paignton [Online]. Zoo, Available: http://www.360imagery.co.uk/virtualtour/leisure/paignton_zoo/. Accessed 2019/10/10.

[47] Berlin Zoo, Personal Guide, [Online]. Available: https://www.zoo-berlin.de/de/aktuelles/news/artikel/appbeacon-co-zoo-berlin-20. Accessed 2019/10/10.

[48] Taronga Zoo, Augmented Reality, [Online]. Available: https://taronga.org.au/media-release/2018-09-06/seetarongas-latest-animal-arrivals-these-holidays. Accessed 2019/10/10.

[49] ZOOM World of Experience Gelsenkirchen, https://www.zoom-erlebniswelt.de/startseite.html. Accessed 2019/10/10.

[50] Rostock Zoo, Virtual Round Tour, [Online]. Available: https://www.tambiente.de/News-virtuell-eroeffnet-appdes-darwineums-im-rostocker-zoo-ab-sofort-zum-download_8137.html. Accessed 2019/10/10.

[51] Landeszooverband Mecklenburg-Vorpommern e.V., Home, [Online]. Available: http://www.landeszooverband-mv.de/. Accessed 2019/10/14.

[52] N. Wulandari, and I. R. Andilolo, "Preliminary Study on the Cashless Payment as an Experience-Based Marketing Vehicle in Tourism Destination" Balancing Development and Sustainability in Tourism Destinations: Proceedings of the Tourism Outlook Conference 2015, Springer, no. 1., pp. 265-275, 2017. Available: https://doi.org/10.1007/978-981-10-1718-6_25 